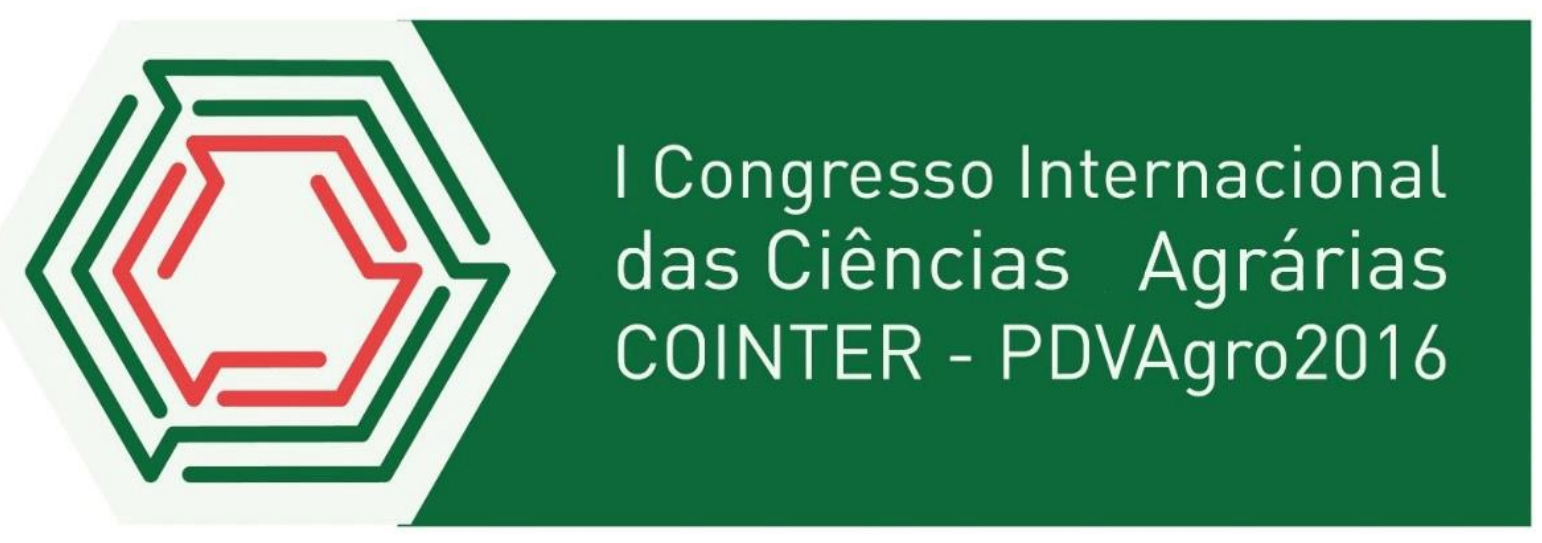

\title{
RÁDIO WEB AGROECOLOGIA: ESTRATÉGIAS PARA UMA NOVA PROGRAMAÇÃO
}

\author{
Apresentação: Relato de Experiência
}

Silvio Gleisson Bezerra ${ }^{1}$; Ollivia Maria Lopes Ventura Galdino ${ }^{2}$; Fabiana Esteves Evangelista $^{3}$ Jorge Luiz Schirmer de Mattos $^{4}$ Francisco Roberto Caporal $^{5}$

\section{Introdução}

Buscando consolidar a Comunicação/Extensão Rural como instrumento de diálogo dos campesinos e dos povos tradicionais com a sociedade, utilizando as potencialidades do suporte rádio web, o Núcleo de Agroecologia e Campesinato/UFRPE, inaugurou em 31/03/2015 a Rádio Web Agroecologia, servindo como espaço de debates acerca da Agroecologia e Campesinato e laboratório para a comunicação popular através da internet (CAPORAL e MATTOS, 2012). Após um ano de atuação, uma equipe do NAC/UFRPE formada por docentes e estagiários, iniciou uma avaliação acerca da atuação da RWA. Desse modo, este documento relata a experiência do autor como profissional de rádio, no papel de facilitador neste processo de avaliação e reorganização da nova programação.

\section{Relato de Experiência}

A partir das audições dos programas e análises dos roteiros, a equipe do NAC/UFRPE identificou como principais obstáculos na atuação da RWA, a produção de conteúdos ainda

\footnotetext{
${ }^{1}$ Curso de Especialização em Docência e Gestão do Ensino Superior, Faculdade Estácio do Recife. E-mail: sgbson@gmail.com

${ }^{2}$ Engenharia Florestal, UFRPE. E-mail: olliviaventura@hotmail.com

${ }^{3}$ Licenciatura em Letras/Espanhol, UFRPE. E-mail: fabiesteves06@gmail.com

${ }^{4}$ Professor de Extensão Rural. NAC/Departamento de Educação, UFRPE. E-mail: js-mattos@hotmail.com

${ }^{5}$ Professor de Extensão Rural. NAC/Departamento de Educação, UFRPE. E-mail: caporalfr@gmail.com
} 
pouco engajados com as temáticas da Agroecologia e o fluxo irregular de produção, tendo como consequências o baixo número de acessos ao site da rádio* e feedbacks dos ouvintes através dos e-mails e comentários em redes sociais. Neste sentido, sugerimos as seguintes ações para a reformulação da programação da RWA: a) organização do fluxo de produção para garantir a regularidade de conteúdos veiculados; b) redefinição das atribuições dos estagiários nas etapas de produção; c) elaboração de um calendário de reuniões de produção.

O processo de reorganização da programação da RWA foi iniciado com a Oficina de Produção de Podcast e Rádio Web, com ênfase na elaboração dos novos programas e reformulação dos já existentes, distribuição orientada pelos conceitos de transversalidade e convergência de conteúdos para a web (JENKINS, 2009), fundamentos da programação de rádio com reorganização da disposição dos programas e análises de fluxo de produção (RIBEIRO e SACRAMENTO, 2010 p. 110).

A Oficina apresentou os seguintes resultados: uma reflexão acerca do primeiro ano de atuação da RWA; a produção de conteúdo mais alinhados com os princípios da Agroecologia; a reorganização do quadro de programas garantindo a regularidade da produção; a organização de uma dinâmica de produção horizontal e colaborativa, com a redefinição das atribuições dos bolsistas nas etapas de criação dos programas; e a elaboração de conteúdos transversais e convergentes para compartilhamento através dos canais de interação com os ouvintes.

\section{Considerações}

A atuação como co-facilitador e colaborador nesse processo, representou para este autor um aprendizado abrangente acerca da Comunicação/Extensão Rural, construída de forma colaborativa por diversos atores, e inserida no contexto das recentes Tecnologias de Informação e Comunicação. Desse modo, experiências neste formato devem ser compartilhadas e estimuladas, ampliando o leque de possibilidades de aprendizado para graduandos dos cursos de Comunicação Social. Além disso, destacamos que enquanto ferramenta de Comunicação/Extensão Rural, a Rádio Web Agroecologia constitui-se em campo de pesquisa promissor, servindo como laboratório de testagem e aprimoramento de modalidades de produção e compartilhamento de saberes e experiências.

\footnotetext{
* A programação da RWA é disponibilizada no site www.radiowebagroecologia.com.br
} 


\section{Referências}

CAPORAL, F.R., MATTOS, J.L.S. Rádio Web Agroecologia: as outras vozes do rádio. Documento oficial, 2012.

GOULART, A.P., SACRAMENTO, I., ROXO, M. (orgs.). História da televisão no Brasil São Paulo: Contexto, 2010.

JENKINS, H. Cultura da convergência: a colisão entre os velhos e novos meios de 